\title{
High Resolution Measurements of the Scour Hole Induced by a Ski-bucket Jet by Means of Structure from Motion
}

\author{
Elsa CARVALHO ${ }^{1}$, Suzana ROSA ${ }^{1}$, Maria Manuela LIMA², \\ and Rui ALEIXO ${ }^{3, 凶}$ \\ ${ }^{1}$ Department of Civil Engineering, Faculty of Engineering, University of Porto, Porto, Portugal \\ ${ }^{2}$ Department of Civil Engineering/School of Engineering, University of Minho, Guimarães, Portugal \\ ${ }^{3}$ CERIS - Instituto Superior Técnico, Universidade de Lisboa, Lisboa, Portugal \\ $\bowtie$ rui.aleixo@tecnico.ulisboa.pt
}

\begin{abstract}
In this article a low-cost high-resolution photogrammetric method is presented to characterize the 3D geometry of scour cavity and bar induced by a ski jump jet. From the obtained 3D model all the main characteristics of the scour cavity and bar: the central longitudinal and transversal scour profiles, maximum scour depth and maximum bar height were determined with resolutions up to $0.0049 \mathrm{~m}$. This technique allowed also to analyse the time evolution of the scour volume.
\end{abstract}

Keywords: photogrammetry, scour cavity and bar, high resolution bed model.

\section{INTRODUCTION}

Photogrammetry is based on a solid mathematical foundation and its details can be found in many textbooks (Konecny 2002). Within photogrammetry, structure from motion (SfM) is a technique to estimate 3 dimensional structures from two-dimensional images, which in a sense, mimics the biological vision of humans (and other animals) that perceive the 3D shapes from the retina projected 2D motion field of a moving object or scene. To the authors' best knowledge there are no applications of SfM to the study of jet induced scour. 


\section{EXPERIMENTAL SETUP AND RESULTS}

The scour experiments were made in the Hydraulics Laboratory of the Faculty of Engineering of Porto University. A stepped spillway equipped with a ski-jump bucket defined by an angle $\alpha=10^{\circ}$, drives the water from an upstream reservoir to a dissipation basin $(1.5 \mathrm{~m} \mathrm{long}, 0.705 \mathrm{~m}$ wide, and $0.70 \mathrm{~m}$ deep). The sand used on these experiments had a $d_{50}=9.92 \times 10^{-3} \mathrm{~m}$, and its density was $\rho_{s}=2650 \mathrm{kgm}^{-3}$. Four conditions made of two flow rates $\left(0.51\right.$ and $\left.0.85 \mathrm{Ls}^{-1}\right)$ and two tailwater depths $(0.03$ and $0.05 \mathrm{~m})$ were tested. Detailed information about the experimental setup can be found in Sá Machado et al. (2019). The bed was scanned with a Canon 7D Mark II, with a sensor of 20 Mpix, and equipped with a $50 \mathrm{~mm} \mathrm{f1.8} \mathrm{lens,} \mathrm{and} 50$ photos were taken, corresponding to the maximum images that the free version of the software Zephyr 3D could handle. It was verified that scanning the bed with a cell phone camera hold similar results (Rosa 2018). The obtained 3D model as further processed in Meshlab and using an in-house built software. Figure $1 \mathrm{a}-\mathrm{c}$ depicts the results for $Q=0.85 \mathrm{Ls}^{-1}$ and $h_{0}=0.05 \mathrm{~m}$. Repeating the same experiment for different times, it was possible to analyse the evolution of the scour volume with time (Fig. 1d). The comparison of the longitudinal profiles with direct physical measurements showed differences in the range of 0.0049 to $0.0073 \mathrm{~m}$ (Rosa 2018).

(a)

(b)
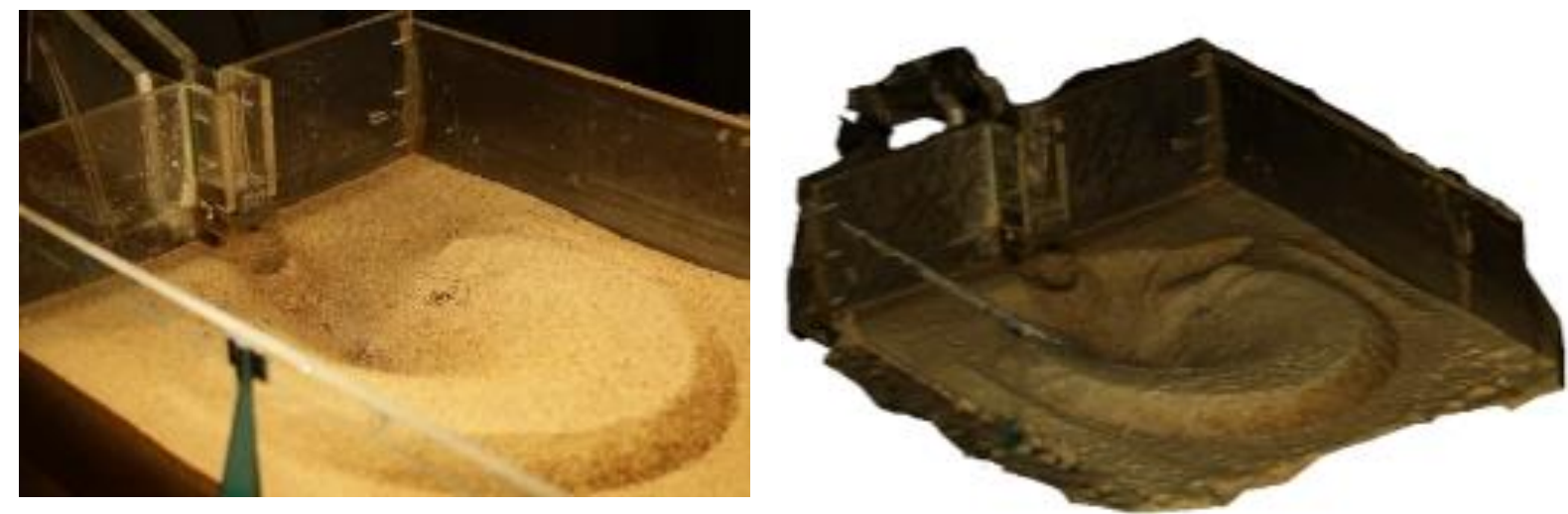

(c)

(d)
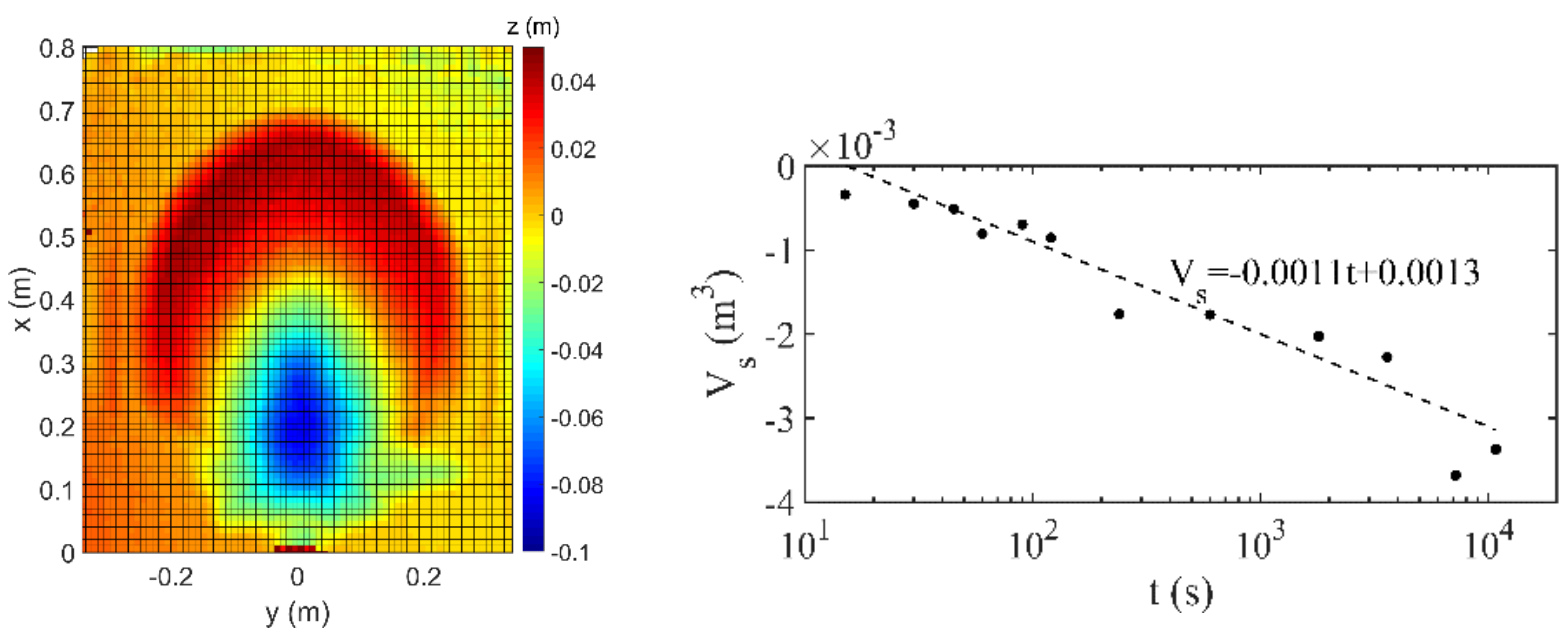

Fig. 1: (a) Photo of the spillway and dissipation basin, (b) obtained 3D model, (c) quantitative results of scour cavity and bar topography, (d) time evolution of the scour for $Q=0.85 \mathrm{Ls}^{-1}$ and $h=0.05 \mathrm{~m}$. 


\section{CONCLUSIONS}

A low-cost, yet accurate and fast, structure from motion photogrammetry technique was applied to the jet induced scour. This technique used the free version of a SfM software (Zephyr 3D), an open-source mesh visualization software (Meshlab) and in-house developed software for post-processing and data analysis. The achieved resolution ranged from 0.0049 to $0.0073 \mathrm{~m}$ or about 5 to 8 grain diameters. Repeating the experiment and applying the same methodology it as possible to determine the time evolution of the scour hole volume and it was observed that it follows a log-law.

\section{References}

Konecny, G. (2002), Geoinformation: Remote Sensing, Photogrammetry and Geographic Information Systems, CRC Press, Boca Raton.

Rosa, S. (2018), Analysis of the ski-bucket angle influence on the erosion downstream of a stepped spillway, MSc. Thesis, Faculty of Engineering of University of Porto (in Portuguese).

Sá Machado, L., M.M.C.L. Lima, R. Aleixo, and E. Carvalho (2020), Effect of the ski jump bucket angle on the scour hole downstream of a converging stepped spillway, Int. J. River Basin Manage. 18, 3, 383-394, DOI: 10.1080/15715124.2019.1586717.

Received 22 March 2021

Accepted 12 April 2021 